\title{
Characterising human agents in the Mekong region
}

\author{
$\underline{\text { A. Smaigl }}^{\text {a }}$ and S. Larson ${ }^{a}$ \\ ${ }^{a}$ CSIRO Ecosystem Sciences, Climate Adaptation Flagship, ATSIP, University Rd, Townsville 4810 QLD \\ alex.smajgl@csiro.au
}

\begin{abstract}
Simulating complex social-ecological processes in an empirical situation faces the challenge of specifying realistic assumptions on system variables. In particular, the characterisation of human behaviour and behavioural responses to perceived changes requires careful implementation. This paper presents methodology developed for an agent-based model for the wider Mekong region, that is, the five countries that Mekong river flows through: China's Yunnan province, Laos, Thailand, Cambodia and Vietnam. The model aims to explore potential side-effects of major development investments, such as mainstream dams, monoculture plantations and large-scale irrigation projects; as well as adaptation strategies to exogenous drivers such as climate change and foreign investment flows. Linking such exogenous and top-down decisions to potential outcomes on the ground, for example, changes in poverty levels, requires modelling of household behaviours that relate to relevant livelihood strategies. Considering the size of the system at stake, inhabited by 270 million people and covering an area of 2.3 million kilometres square, characterisation and parameterisation of human agents and their behaviour requires robust methodology. This paper outlines a mixed resolution approach for the model design and discusses methodology employed to inform model assumptions with real-world data.
\end{abstract}

Keywords: $\quad$ Agent-based modelling, parameterisation, Mekong. 


\section{INTRODUCTION}

Over the past decade many developing countries have experienced substantial boosts in foreign direct investment that, in some parts of the world, dwarf aid directed investments to a point where donors struggle to remain relevant. Consequently, poverty alleviation goals are increasingly becoming a side-effect of macro-political decisions that are largely responding to foreign investment opportunities, which seek access to natural resources or labour. This shift has been observed for the wider Mekong region with large investment influx from China, Thailand and Vietnam aspiring access to the water, food or energy sectors of Lao PDR, Cambdia and Myanmar (Middleton, Garcia, \& Foran, 2009; Molle, Foran, \& Floch, 2009). While most investors aim for achieving their own national goals related to water, food and energy, two dimensions remain mainly unexplored (Smajgl, Foran, Dore, Ward, \& Larson, forthcoming): Firstly the understanding of trade-offs between water, food and energy, and, secondly, the analysis of trans-boundary implications.

Methodologically the challenge arises to integrate the multiple disciplines relevant to this nexus in a transboundary context as some dynamics, such as migration and financial investment, create a high level of connectivity between the six countries. This participatory research employs agent-based modelling as one method for assessing decisions from an integrated complex systems perspective (Smajgl, et al., forthcoming). The following section provides the necessary background on the wider Mekong region. Then, the overarching methodology is conceptualised, entailing the development of an agent-based model for the Mekong region. The model design is currently in its final stage of implementation. Then, the paper provides details on the parameterisation approach for human agents and concludes with a discussion on challenges for applied agent-based modelling.

\section{THE WIDER MEKONG REGION}

The Mekong region comprises of Vietnam, Cambodia, Laos PDR, Thailand, Myanmar and Yunnan (China) (Dore, 2003; Theeravit, 2003). Development has elevated the demand for many commodities including electricity, natural resources and manufactured goods. Sourcing and satisfying commodity demand from neighbouring countries has contributed to an increasing connectivity within the Mekong region. In particular substantial migration, the sourcing and manufacturing of natural resources, and financial flows contribute to this high level of connectivity among Mekong region countries.

High regional connectivity implies that decisions made in one part of the region are likely to have implications for other parts of the region. According to complex systems theory (Barkley, 2001; Castellani \& Hafferty, 2009; Holling, 1973; Smajgl, Izquierdo, \& Huigen, 2010), the simultaneous implementation of multiple diverse decisions is likely to result in unpredicted consequences. In the Mekong region the current list of pending local decisions include:

- Mainstream dams in the lower Mekong basin, in particular in Lao PDR and Cambodia

- Large scale water diversion, in particular in Thailand and Lao PDR

- Investments in response to sea level rise, in particular in Vietnam's Mekong Delta

- Land use changes in response to accelerated increases in rubber demand

Scoping activities with stakeholders in the Mekong region identified that the cumulative impact of combinations of these listed development strategies is perceived as a potential risk for long-term outcomes and that such cumulative, regional assessment has not been carried out yet. Additionally, the majority of such decision making and planning processes are taking place in national and sectoral silos. Some coordination efforts are well implemented such as the Mekong River Commission with its focus on the Mekong Basin and its water resources or the working groups facilitated by the Asian Development Bank initiated as part of their GMS (Greater Mekong Subregion) initiative. However, first scoping of the participatory process has revealed that coordination between water-food and energy related decisions within and across Mekong region countries is rather sub-optimal.

\section{METHODOLOGY}

The work presented in this paper follows a learning paradigm that aims to facilitate a workshop-based process in which stakeholders consider possible development strategies in the light of their visions and the best available scientific insights (Smajgl, 2010a). This involves a participatory process with six steps:

1. Identification of pending decisions,

2. Development of explicit visions for local and regional development,

3. Identification of causal beliefs key stakeholders hold,

4. Assessment of sectoral and cross-sectoral impacts of pending decisions,

5. Comparison of initial beliefs and research results (=alternative beliefs),

6. If necessary, amendment of beliefs/visions/decisions. 
In a participatory research approach stakeholders are involved before the actual work starts to help scoping out the actual issues and make choices on relevant decision making or planning processes, on geographical foci, and on methodological requirements. Details of the overarching methodology implemented with various government and research agencies in the Mekong region is provided in Smajgl et al. (forthcoming). While the principle approach is rather simple, the implementation in the wider Mekong regions becomes complicated due to the multiple levels of multiple independent governments.

Large-scale decisions, as the ones listed above, are made within the boundaries of sovereign countries and partly at provincial or district levels. Additionally, economic links, political bonds and activities of supranational agencies introduce changes with implications for various countries. Thus, the development of visions and the process of contesting beliefs have to be implemented iteratively. Visions are first drafted within each country. Then, draft visions are presented to decision makers and decision influencers in other countries to identify trans-boundary implication. This leads to revised visions that are likely to be more consistent as they consider visions held by decision makers elsewhere in the Mekong region.

Research activities are focused on critical assumptions decision makers and decision influencers construct. This includes questions on, for instance, household responses to changes, availability of water, and changes in agricultural production and national food access. Critical for the identification of potential risks emerging from cross-sectoral trade-offs and trans-boundary implications is the integrated analysis of key socialecological processes. The main method for achieving this integration and for providing a tool to facilitate discussions that challenge stakeholder beliefs is agent-based modelling.

Agent-based modelling allows the simulation of systems in a bottom-up perspective without imposing technical challenges for crossing disciplinary boundaries. In particular the ability to model explicitly human decision making processes triggered a quick uptake by many disciplines (Bousquet \& Le Page, 2004; Gilbert, 2008). However, this strength comes at a cost as attributes and behaviour of human agents and how they change need to be specified for any model application (Bohensky, Smajgl, \& Herr, 2007; Smajgl, Brown, Valbuena, \& Huigen, 2011). This paper is focused on providing details on the methodology for characterising human agents in this model for the wider Mekong region.

\section{MODEL CHARACTERISATION AND PARAMETERISATION}

Technically, the model links investment outcomes as perceived by agents to policy-relevant indicators such as poverty. The critical dimension in this highly complex relationship between such macro-policy interventions and poverty are livelihoods and how households adjust their livelihood strategies in response to perceived changes. Such household adaptation is captured for the context of policy-motivated changes as well as for climate change. This means that households need to be characterised and livelihood-related behaviours and responses need to be specified.

This step of characterising and parameterising human agents is the Achilles' heel of applied agent-based modelling as this methodological domain has not been systematically explored and tested (Smajgl, Brown, et al., 2011). Two principle methods dominate the applied agent-based modelling community: (1) An assumingly representative sample is surveyed and responses are proportionally up-scaled to inform assumptions for the whole agent population. (2) A sample is surveyed and the resulting data is up-scaled by other means to achieve different proportions in the whole agent population than in the sample. This second approach requires additional information, such as disaggregated household-level census data or GIS data. In many cases it also requires the development of explicit typologies (Bohensky, et al., 2007; Marshall \& Smajgl, forthcoming; Smajgl \& Bohensky, forthcoming).

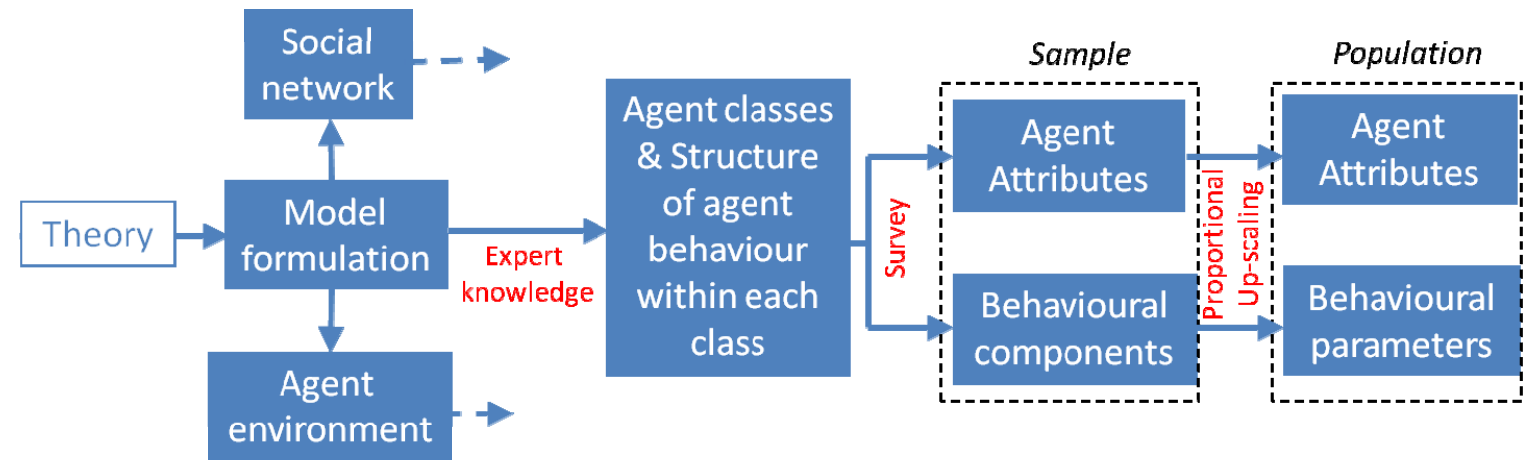

Figure 1. Framework for parameterisation of ABM, adapted from Smajgl, et al. (2011) 
For this applied modelling exercise the characterisation and parameterisation approach is described based on the framework developed by Smajgl, et al. (2011), see Figure 1. In a first step experts were interviewed to generate a list of principle agent classes, distinguishing for instance between urban and rural households and identifying the key livelihoods with their respective activities. Households (Meta class) have the ability to engage in 36 livelihoods (e.g. rice, rubber plantations, fishing, farm labour, manufacturing industry, construction, mining, government employee or tourism). Each livelihood comes with a diary of activities, which are partly linked to environmental events, such as rainfall. Household activities impact on environmental entities, of which the model represents spatial entities (attributes: soil type, slope, land cover, administration), fish and various crops, (e.g. rice, trees). Households respond to environmental changes as well as to government interventions or market signals. Figure 2 conceptualises the main entities.

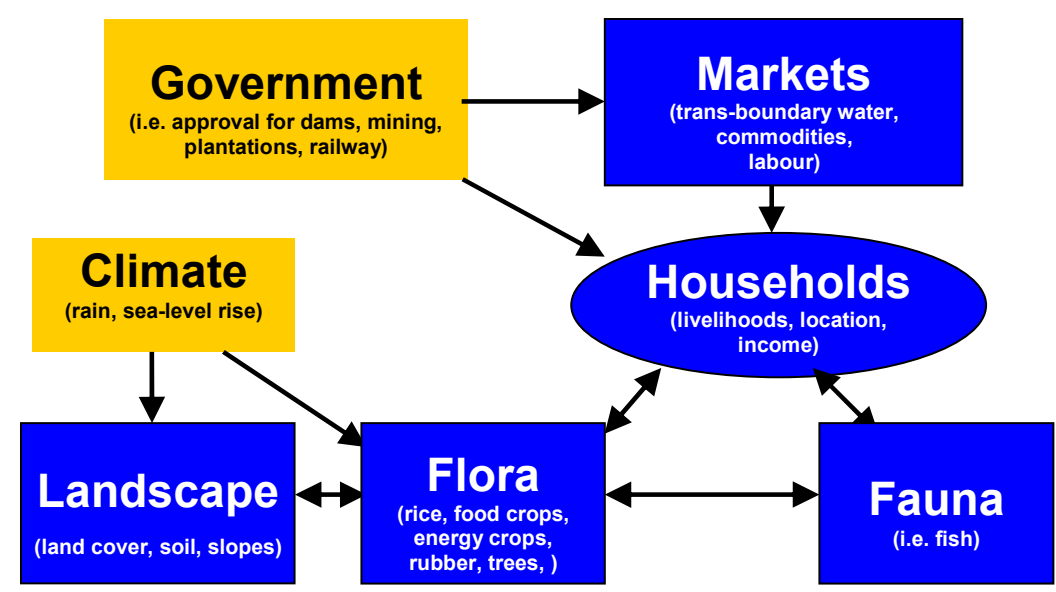

Figure 2. Conceptualisation of Mekong region model

In a second step a survey was conducted eliciting in each of the five focus-areas data from 1,000 households. This survey identifies household attributes and household intentions. Attributes include the household location, the household size, education, ethnicity, livelihoods, assets, and income. It is also recorded if household members (temporarily) migrate to carry out their livelihood. Results from the survey carried in out in the Lao focus area should exemplify the diversity of household attributes. The Lao focus area had an average household size of 5.7 and 670 of the 1,000 responses were depending on rice. The second most relevant livelihood is employment in the government with 117 responses. Income is distinguished between activities linked to the market economy and other production (largely for selfsufficiency). The average household income (derived from paid labour only) is US\$5.50 per day per household, ranging from an annual income of nil (in 165 cases) to a maximum of US\$46,000.

Household intentions are elicited in the context of pending policy decisions or impacts of climate change expected by macro-policy makers, see Table 1. These behavioural responses are collated for specific potential changes, which are listed in Table 1. Every household was asked to imagine a certain change, such as a substantial and lasting drop in household income. Behavioural responses to changes such as an enduring drop in household income are categorised in the following behavioural dimensions:

- Changes in the livelihood strategy, including

○ migration, as individual migration or migration of the household,

$\circ$ the anticipated place of living,

$\circ$ asset-related strategies (i.e. selling/purchasing land), and

- the identification of behavioural impediments.

Using again the Lao example to provide some insight into the diversity in behavioural responses,

- 350 out of 1,000 respondents said that they would not change anything (despite a drop in income by $50 \%$ for at least 5 years),

- 416 responded that they would stay but change their livelihood (largely changing or adding crops),

- 33 declared to migrate out but maintain their livelihood, and

- 202 said that they would out migrate and change their livelihood.

This sample is proportionally up-scaled to specify attributes for the whole agent-population, which assumes a representative dataset. As the participatory process links to decision making processes in five key areas, the model needs to simulate human behaviour in these areas at the disaggregated household level. Outside of these areas, human and social aspects are simulated as much more aggregated entities. Assumptions on how household attributes change outside of the high-resolution areas was developed with experts utilising 
all five data sets according to what livelihoods dominate. Considering the representation of dynamics related to the same entity (households) at different resolutions we refer to this approach as the "mixed resolution approach" (Smajgl, 2010b), which implies that households can migrate out of high-resolution areas into low-resolution areas and back into a high-resolution area. Such a mixed-resolution approach is quite common GIS modelling but largely as static properties, while here household entities are dynamic and can be dissolved depending on their location.

Technically, if conditions are changed that are represented in Table 1 agents adapt according to the intentional data. Conditions can be changed (exogenously) by the model user or changes emerge (endogenously) during the simulation.

Table 1: List of potential changes for household survey on intentional data (* means this question was considered)

\begin{tabular}{|c|c|c|c|c|c|c|}
\hline Potential changes & $\begin{array}{l}\text { Cam- } \\
\text { bodia }\end{array}$ & Lao & Thai & $\begin{array}{l}\text { Viet- } \\
\text { Lower }\end{array}$ & $\begin{array}{l}\text { Viet- } \\
\text { Upper }\end{array}$ & Yunnan \\
\hline $\begin{array}{l}\text { Imagine that your profit - and/or production }- \text { and/or } \\
\text { wages - from your main activity goes down by half, and is } \\
\text { likely to stay that low for at least five years }\end{array}$ & $*$ & * & * & $*$ & $*$ & $*$ \\
\hline $\begin{array}{l}\text { Imagine that a lot of employment in industry will be } \\
\text { available and most people from your village will move to } \\
\text { cities to work in factories }\end{array}$ & $*$ & $*$ & $*$ & $*$ & $*$ & $*$ \\
\hline $\begin{array}{l}\text { Imagine that catch of fish, aquatic animals and plants by } \\
\text { your HH reduces by half, and is likely to stay that way for } \\
\text { at least five years. }\end{array}$ & $*$ & & & $*$ & & \\
\hline $\begin{array}{l}\text { Imagine that your access to traders is twice as good as } \\
\text { now or that your travel time to markets halves }\end{array}$ & $*$ & & & & & \\
\hline $\begin{array}{l}\text { Imagine that irrigation systems are built and there is } \\
\text { sufficient water in the catchment to grow crops all year } \\
\text { round }\end{array}$ & & $*$ & & & & \\
\hline Imagine that weather becomes variable and unpredictable. & & & $*$ & & & $*$ \\
\hline $\begin{array}{l}\text { Imagine that in the future competition for water doubles, } \\
\text { and that there are many more users competing for water, } \\
\text { some of these users not from agriculture. }\end{array}$ & & * & $*$ & & & \\
\hline $\begin{array}{l}\text { Imagine that water becomes more brackish, and this } \\
\text { brackish water arrives earlier in the season and leaves } \\
\text { later }\end{array}$ & & & & $*$ & & \\
\hline $\begin{array}{l}\text { Imagine that small insufficient floods (like in 2010) come } \\
\text { twice as often }\end{array}$ & & & & & $*$ & \\
\hline $\begin{array}{l}\text { Imagine that big damaging floods (like 2000) come twice } \\
\text { as often }\end{array}$ & & & & & $*$ & \\
\hline $\begin{array}{l}\text { Imagine the government announces payments such that } \\
\text { you can plant native trees, and become a tree farmer } \\
\text { rather than rubber (or other major activity) farmer and still } \\
\text { maintain your standard of living }\end{array}$ & & & & & & $*$ \\
\hline
\end{tabular}

\section{DISCUSSION}

Agent-based modelling offers a promising technique for tackling in applied research highly complex issues, in particular by providing methodology to simulate human decision making processes. However, situations such as the analysis of potential outcomes of development strategies in the highly connected Mekong Region require robust techniques to inform model assumptions with real-world data. Otherwise learning effects are likely to be limited or even misleading. To test options for improving methodological robustness, model characterisation and parameterisation techniques need to be (1) identified and (2) systematically tested in diverse contexts. This paper provides details on how to sequence parameterisation steps in situations with large populations and high behavioural diversity. Most applied agent-based modelling publications lack this transparency and the provision of structured presentation of methodological details (Berger \& Schreinemachers, 2006; Smajgl, Brown, et al., 2011). The survey-based approach described in this paper delivers a database ensuring high consistency with the policy interests as all policy relevant investment options are explicitly considered. Additionally, behavioural dimensions are considered according to policy relevant indicators. Proportional up-scaling might be a weak point in this approach as minorities can be easily over-represented - if minority such as free-riders are captured in the sample - or unrepresented - if not captured in the sample. However, disproportional up-scaling requires additional census-type data sets and (often) explicit typologies, which many applied contexts do not provide. (Such 
changes in proportions of agent types introduce also additional uncertainties, which could outweigh the initial gains.) The next step in this approach will be to conduct the participatory assessment work and advance validation to allow for assessing the parameterisation sequence chosen. While agent-based modelling experiences also deficits in the validation domain (Smajgl, House, \& Butler, 2011) it seems paramount to test parameterisation techniques in different contexts and understand which methodological option leads in which circumstances to the most robust model assumptions. Such an effort to improve agent-based methodology requires a larger community to allow modelling groups to learn from each other.

\section{ACKNOWLEDGEMENTS}

The authors wish to thank Lilao Bouapao, Su Yufang, Dang Kieu Nhan and Nguyen Hieu Trung for their efficient collaboration in conducting the household survey, Aurelie Delisle for her excellent work on collating the data base, and Prof Dr Andreas Ernst and Martijn van Grieken for their constructive comments. This research is funded by the CSIRO AusAID Research for Development Alliance.

\section{REFERENCES}

Barkley, R., Jr. (2001). Complex ecologic-economic dynamics and environmental policy 168. Journal of Ecological Economics, 37, 23-37.

Berger, T., \& Schreinemachers, P. (2006). Creating Agents and Landscapes for Multiagent Systems from Random Samples. Ecology and Society, 11(2).

Bohensky, E., Smajgl, A., \& Herr, A. (2007, 2007). Calibrating behavioural variables in agent-based models: Insights from a case study in East Kalimantan, Indonesia. Paper presented at the MODSIM 2007 International Congress on Modelling and Simulation.

Bousquet, F., \& Le Page, C. (2004). Multi-agent simulations and ecosystem management: a review. Ecological Modelling, 176(3-4), 313-332.

Castellani, B., \& Hafferty, F. (2009). Sociology and Complexity Science: A New Field of Inquiry. Berlin, Heidelberg: Springer.

Dore, J. (2003). The governance of increasing Mekong regionalism. In M. Kaosa-ard \& J. Dore (Eds.), Social Challenges for the Mekong Region (pp. 405-440). Bangkok: White Lotus.

Gilbert, N. (2008). Agent-based models. Los Angeles: SAGE Publications.

Holling, C. S. (1973). Resilience and stability of ecological systems. Annual Review of Ecology and Systematics, 4, 1-24.

Marshall, N. A., \& Smajgl, A. (forthcoming). Understanding types of cattle graziers in the Burdekin River region, Australia, based on their adaptive capacity to climate variability and level of resource dependency. Rangeland Ecology and Management.

Middleton, C., Garcia, J., \& Foran, T. (2009). Old and New Hydropower Players in the Mekong Region: Agendas and Strategies. In F. Molle, T. Foran \& M. Käkönen (Eds.), Contested Waterscapes in the Mekong Region (pp. 23-54). London, UK; Sterling, VA: Earhscan.

Molle, F., Foran, T., \& Floch, P. (2009). Changing Waterscapes in the Mekong Region: Historical Background and Context. In F. Molle, T. Foran \& M. Käkönen (Eds.), Contested Waterscapes in the Mekong Region: Hydropower, Livelihoods and Governance (pp. 1-21). London: Earthscan.

Smajgl, A. (2010a). Challenging beliefs through multi-level participatory modelling in Indonesia. Environmental Modelling and Software, 25(11), 1470-1476.

Smajgl, A. (2010b). Large-scale empirical agent-based modelling through multi-model and mixedresolution approach. Paper presented at the World Congress on Social Simulation.

Smajgl, A., \& Bohensky, E. (forthcoming). Behavioural heterogeneity in agent-based modelling: Insights from a case study in East Kalimantan, Indonesia Environmental Modelling and Software.

Smajgl, A., Brown, D. G., Valbuena, D., \& Huigen, M. G. A. (2011). Empirical characterisation of agent behaviours in socio-ecological systems. Environmental Modelling \& Software, 26(7), 837-844.

Smajgl, A., Foran, T., Dore, J., Ward, J., \& Larson, S. (forthcoming). Visions, beliefs and transformation: Methods for understanding cross-scale and trans-boundary dynamics in the wider Mekong region. Eology and Society.

Smajgl, A., House, A., \& Butler, J. (2011). Implications of ecological data constraints for integrated policy and livelihoods modelling: an example from East Kalimantan, Indonesia Ecological Modelling, 222, 888-896.

Smajgl, A., Izquierdo, L., \& Huigen, M. G. A. (2010). Rules, Knowledge and Complexity: How Agents Shape their Institutional Environment. Journal of Modelling and Simulation of Systems, 1(2), 98-107.

Theeravit, K. (2003). Relationships within and between the Mekong Region in the context of globalisation. In M. Kaosa-ard \& J. Dore (Eds.), Social Challenges for the Mekong Region (pp. 49-80). Bangkok: White Lotus. 